DOI: http://doi.org/10,21009/JKKP.072.10

\title{
ANALISIS PELAKSANAAN PROGRAM KELUARGA HARAPAN (PKH) DALAM RANGKA PENGURANGAN ANGKA KEMISKINAN DI KABUPATEN BANTUL TAHUN 2018
}

\author{
Sukma Aprilia Puntorini ${ }^{1, a)}$ Eko Priyo Purnomo ${ }^{\left.1,{ }^{*} \mathrm{~b}\right)}$ \\ 1 Departmen of Government Affairs and Administration, Jusuf Kalla School of Government, \\ Universitas Muhammadiyah Yogyakarta, Indonesia
}

Email: a)Sukma.a.isip17@mail.umy.ac.id, ${ }^{* b}$ eko@umy.ac.id

\begin{abstract}
Abstrak
Penelitian ini bertujuan untuk menganalisis pelaksanaan Program Keluarga Harapan (PKH) dalam rangka pengurangan angka kemiskinan di Kabupaten Bantul Tahun 2018. Metode yang digunakan dalam penelitian ini adalah metode kualitatif jenis data yang digunakan adalah data sekunder, data sekunder yaitu mengumpulkan data dan informasi yang didapat dengan melalui dokumentasi atau arsip yang ada di Kabupataen Bantul. Hasil penelitian menunjukkan bahwa Kabupaten Bantul mengetahui sejauh mana pemahaman masyarakat tentang PKH yaitu dengan sosialisasi, serta memberikan pelatihan kewirausahaan agar Keluarga Penerima Manfaat (KPM) dapat lebih produktif. Dengan adanya PKH tersebut dapat menjadikan KPM lebih produktif, sebab terdapat pelatihan kewirausahaan. Pelatihan kewirausahaan tersebut, dapat menjadikan KPM lebih kreatif serta dapat meningkatkan pendapatan dalam keluarganya. Selain itu Kabupaten Bantul masih memiliki beberapa hambatan dalam melaksanakan PKH. Hambatan PKH di Kabupaten Bantul adalah minimnya dana untuk memberikan sarana dan prasarana pendukung bagi pelaksana $\mathrm{PKH}$, kurangnya ketersediaan sumber daya manusia yaitu pendamping $\mathrm{PKH}$, menurunnya kepatuhan peserta $\mathrm{PKH}$, dan data penerima $\mathrm{PKH}$ tidak diperbarui sehingga kurang tepat sasaran. Maka sebaiknya, program PKH ini melibatkan pemerintahan desa agar ada yang memonitoring secara langsung, Masyarakat memenuhi kewajiban-kewajiban sebagai peserta $\mathrm{PKH}$, dan adanya pembaruan data peserta $\mathrm{PKH}$.
\end{abstract}

Kata kunci: analisis, kemiskinan, PKH, sosialisasi.

\section{Analysis of The Implementation of The PKH In The Context Of Reducing Proverty Rate In Bantul Regency in 2018}

\begin{abstract}
This study aims to analyze the implementation of the Family Hope Program (PKH) in the context of reducing the poverty rate in the Bantul Regency in 2018. The method used in this study is qualitative, the type of data used is secondary data, secondary data, namely collecting data and information obtained through documentation or archives in Bantul Regency. The results showed that Bantul Regency knew the extent of community understanding of $\mathrm{PKH}$, namely through socialization, as well as providing entrepreneurship training so that beneficiary families (KPM) could be more productive. Also, Bantul Regency still has several obstacles in implementing PKH. With the PKH, it can make KPM more productive, because there is entrepreneurship training. This entrepreneurship training can make KPM more creative and can increase income in the family. Also, Bantul Regency still has several obstacles in implementing PKH. The obstacles to PKH in Bantul Regency are the lack of funds to provide supporting facilities and infrastructure for $\mathrm{PKH}$ implementers, the lack of availability of human resources, namely PKH facilitators, decreased compliance of PKH participants, and PKH recipient data not being updated so that it is not well-targeted. So it is better if this PKH program involves the village government so that someone monitors it directly, the community fulfills its obligations as $\mathrm{PKH}$ participants, and there is updating of PKH participant data.
\end{abstract}

Keywords: analysis, $\mathrm{PKH}$, poverty, socialization 


\section{PENDAHULUAN}

Program Keluarga Harapan (PKH) adalah program dengan membagikan sumbangan atau bantuan langsung pada masyarakat untuk meningkatkan kualitas hidup melalui akses pendidikan dan kesehatan (Suleman \& Resnawaty, 2018). Program Keluarga Harapan (PKH) dilakukan pemberdayaan keluarga miskin yang memenuhi persyaratan untuk meningkatkan kualitas sumber daya manusia dalam bidang kesehatan dan pendidikan. Selain itu, Program Keluarga Harapan (PKH) juga dilakukan sebagai bentuk pelaksanaan Undang-Undang Nomor 40 Tahun 2004 tentang jaminan sosial, maka diterapkannya Program KeluargaHarapan (PKH).

Dalam bidang pendidikan, PKH bertujuan untuk mengurangi angka putus sekolah, khususnya bagi keluarga miskin dan mengurangi pekerja anak di Indonesia. Sedangkan dalam bidang kesehatan bertujuan untuk mengurangi angka kematian bayi dan memenuhi gizi balita dan anak. Selain itu, juga membawa efek pendapatan untuk Rumah Tangga Sangat Miskin (RTSM) atau Keluarga Sangat Miskin (KSM) dengan mengurangi pengeluaran rumah tangga. Minimnya penghasilan membuat masyarakat tersebut sulit untuk memenuhi kebutuhan khususnya dalam bidang pendidikan dan kesehatan. Sasaran utama PKH adalah Keluarga Sangat Miskin (KSM) berdasarkan data yang diperoleh dari Badan Pusat Statistik (BPS).

Dampak jangka pendek dari $\mathrm{PKH}$ adalah memotong pengeluaran rumah tangga, penerima PKH dapat menggunakan bantuan tersebut untuk kebutuhan anak sekolah. Itu artinya penerima $\mathrm{PKH}$ tidak terlalu memikirkan biaya anak-anaknya. Meskipun bantuan tersebut belum mencukupi kebutuhan sekolah, namun setidaknya dapat mengurangi pengeluaran rumah tangga penerima PKH. Pemerintah membuat Program Keluarga Harapan (PKH) sejak tahun 2007, dalam rangka menanggulangi kemiskinan. Sebagaimana dalam Peraturan Menteri Sosial Nomor 1 Tahun 2018 Pasal 1 Ayat 1, PKH merupakan program yang diberikan kepada keluarga miskin bersyarat dengan memberikan bantuan sosial yang masuk daftar dalam data program penanganan fakir miskin, yang diolah oleh Pusat Data dan Informasi Kesejahteraan Sosial dan dipastikan sebagai Keluarga Penerima PKH. Sedangkan untuk jangka panjang PKH diharapkan mampu memotong rantai kemiskinan.

Kemiskinan adalah keadaan dibawah garis standar kebutuhan minimum atau batas kemiskinan. Kemiskinan adalah suatu masalah karena kurangnya pendapatan atau kekayaan untuk mencukupi kebutuhan dasar. Faktor penyebab tingginya angka kemiskinan salah satunya adalah ketertinggalan dan penghambatan dalam pembangunan (Sahib, M, 2016). Menurut Auliah, R dan Tb, T. I (2019), criteria kemiskinan dari BPS adalah:

a. Tidak miskin

Adalah memiliki pengeluaran perbulannya lebih dari Rp. 350.610.

b. Hampir tidak miskin

Adalah memiliki pengeluaran perbulan perkepala antara Rp. 280.488 s/d Rp.350.610 atau sekitar Rp. $9.350 \mathrm{~s} / \mathrm{d}$ Rp. 11. 687 per orang dalam satu hari.

c. Hampir miskin

Adalah memiliki pengeluaran perbulan dan kepala antara Rp. $233.740 \mathrm{~s} / \mathrm{d} 280.488$ atau sekitar Rp. 7.780 s/d Rp. 9.350 per orang dalam satu hari.

d. Miskin

Adalah memiliki pengeluaran perorang perbulan perkepala Rp. 233.740 kebawah atau sekitarRp. 7.780 kebawah perorang dalam satu hari.

e. Sangat miskin

Adalah tidak ada patokan berapa pengeluaran perorang dalam satu hari. 
Faktor-faktor penyebab kemiskinan yang pertama adalah pendapatan. Pendapatan adalah total penghasilan yang diterima oleh individu atas pekerjaannya selama satu periode tertentu. Kedua adalah pendidikan. Pendidikan dan kemiskinan sangat berhubungan erat. Kemiskinan adalah kegagalan dalam pendidikan (Auliah, 2019). Ketiga, kesehatan adalah bagian langsung dari kesejahteraan manusia dan bentuk asset manusia dalam meningkatkan kemampuan individu. Terakhir, konsumsi (pengeluaran) adalah penggunaan barang atau jasa secara langsung untuk memenuhi kebutuhan manusia. Konsumsi berpengaruh terhadap tingkat kemiskinan artinya semakin besar konsumsi maka tingkat kemiskinan akan turun (Auliah, 2019).

Program Keluarga Harapan (PKH) tidak sama dengan Bantuan LangsungTunai (BLT) yang telah terlaksana selama ini dalam rangka menolong masyarakat miskin. Program Keluarga Harapan (PKH) sebagai usaha untuk membangun system perlindungan social penduduk miskin untuk mempertahankan dan meningkatkan kesejahteraan penduduk miskin dan memutus rantai kemiskinan (Sahib, 2016). Program Keluarga Harapan (PKH) adalah sebuah program bantuan social bersyarat dan membuka akses keluarga miskin terutama ibu hamil dan anak untuk menggunakan berbagai fasilitas layanan kesehatan, pendidikan atau membuka usaha kecil (Putri, 2019). Tujuan dari Program Keluarga Harapan (PKH) adalah menunjukkan kualitas sumber daya manusia dan mengubah sikap, pandangan dan perilaku Rumah Tangga Sangat Miskin (RTSM) agar lebih dapat mudah menggunakan layanan kesehatan dan pendidikan sehingga dapat memotong rantai kemiskinan (Sahib, 2016).

Menurut Putri (2019) pemberian bantuan dilaksanakan setahun dalam 2 sampai 4 tahap yaitu pada bulan Maret, Juni, September, November, dan ini adalah ketentuan dari pemerintah pusat.Permensos 1 Tahun 2018 tentang Program Keluarga Harapan pasal 3, menyebutkan bahwa sasaran Program Keluarga Harapan (PKH) adalah keluarga dan/atau seseorang yang miskin dan rentan serta terdaftar dalam Data Terpadu Program Penanganan Fakir Miskin yang memiliki komponen kesehatan, pendidikan, dan/atau kesejahteraan social (Angraeni, 2019). Menurut Afrizal \& Eliza (2020), dalam Permensos Nomor 1 Tahun 2018, tujuan Program Keluarga Harapan (PKH) adalah:

a. Meningkatkan taraf hidup Keluarga Penerima Manfaat dengan layanan kesehatan, pendidikan dan kesejahteraan social.

b. Menurunkan beban pengeluaran dan meningkatkan pendapatan keluarga miskin dan rentan.

c. Mengubah perilaku dan kemandirian Keluarga Penerima Manfaat dalam mengakses layanan kesehatan dan pendidikan serta kesejahteraan social.

d. Memotong kemiskinan dan kesenjangan.

Program Keluarga Harapan (PKH) diharapkan dapat menunjang keluarga kurang mampu atau miskin untuk menaikkan kualitas hidup dan mengurangi kemiskinan. Kemiskinan adalah suatu keadaan ketidakmampuan untuk memenuhi kebutuhan utamanya (Hidayat, 2018). Suatu individu atau kelompok dikatakan miskin apabila tidak dapat memenuhi kebutuhan dasar, mengakses pelayanan kesehatan dan pendidikan sehingga kehidupannya dikatakan tidak sejahtera. Sejahtera adalah situasi suatu individu yang mampu mencukupi kebutuhan selain kebutuhan dasar.

Program Keluarga Harapan (PKH) tidak sepenuhnya dapat mengurangi kemiskinan. Kekurangan dari $\mathrm{PKH}$ adalah data penerima $\mathrm{PKH}$ yang tidak selalu diperbarui sehingga kurang tepat sasaran. Namun, bantuan PKH sudah sampai di berbagai daerah, salah satunya adalah Kabupaten Bantul. Pada tahun 2018 Kabupaten Bantul adalah kabupaten yang memiliki penduduk miskin tertinggi di Provinsi Daerah Istimewa Yogyakarta (DIY). 


\begin{tabular}{rrrrrrrr}
\hline NO & KABUPATEN & \multicolumn{7}{c}{ TAHUN } \\
& & $\mathbf{2 0 1 3}$ & $\mathbf{2 0 1 4}$ & $\mathbf{2 0 1 5}$ & $\mathbf{2 0 1 6}$ & $\mathbf{2 0 1 7}$ & $\mathbf{2 0 1 8}$ \\
\hline 1. & Bantul & $16,48 \%$ & $15,89 \%$ & $16,33 \%$ & $14,55 \%$ & $14,07 \%$ & $13,43 \%$ \\
\hline
\end{tabular}

(Sumber: Data ini di ambil dari website Badan Pusat Stastik (BPS) Kabupaten Bantul Tahun 2018).

Berkaitan dengan data diatas, maka perlu dilakukan penelitian dengan metode penelitian kualitatif tentang Analisis Pelaksanaan Program Keluarga Harapan (PKH) dalam Rangka Pengurangan Angka Kemiskinan di Kabupaten Bantul Tahun 2018.

Berdasarkan uraian latar belakang permasalahan yang telah dipaparkan seperti diatas, penelitian ini merumuskan bahwa permasalahan dalam penelitian ini adalah angka kemiskinan di Kabupaten Bantul paling tinggi di Provinsi Daerah Istimewa Yogyakarta pada tahun 2018. Maka peneliti membuat perumusan masalah penelitian "Menganalisis bagaimana Pelaksanaan Program Keluarga Harapan (PKH) dalam Rangka Pengurangan Angka Kemiskinan di Kabupaten Bantul Tahun 2018?".

\section{METODE}

Metode penelitian adalah kaidah keilmuan agar memperoleh informasi serta kegunaan tertentu dimana kaidah keilmuan itu memiliki maksud jika aktivitas penelitian itu berdasarkan pada tanda-tanda keilmuanya itu empiris, sistematis dan rasional (Sugiyono,2010). Disini saya mengambil metode penelitian kualitatif. Metode penelitian naturalistic atau Metode penelitian kualitatif digunakan untuk meneliti pada suatu materi ilmiah, maksudnya pengkaji adalah menjadi instrument pokok, cara dalam mengumpulkan data atau informasi dengan analisis data atau informasi yang bersifat induktif, serta hasil dari penelitian kualitatif lebih mementingkan maksud atau arti dibandingkan menyamaratakan (Sugiyono,2010). Metode penelitian atau observasi kualitatif adalah suatu metode dalam suatu observasi yang mendapatkan informasi dan data dalam bentuk gambaran yang mana informasi dan data tersebut diperoleh berupa lisan atau tulisan dari masyarakat atau sikap yang kita amati (Moleong, 2008).

Sedangkan observasi atau penelitian kualitatif adalah bentuk penelitian yang memperoleh kreasi-kreasi yang tidak dapat diperoleh dengan memakai metode statistic atau pun system kuantifikasi yang lainnya (Afifuddin dan Saebeni, 2009). Kegiatan dalam menganalisis data kualitatif dilaksanakan dengan saling berinteraksi dan dilaksanakan dengan berkelanjutan hingga akhir (Sugiyono,2010). Teknik analisis data yaitu dengan reduksi data, mereduksi data adalah merangkum, yaitu proses memilih, memusatkan, serta perhatian dalam menyederhanakan, abstaksi, dan transformasi data kasar yang diperoleh dilapangan studi. (Sugiyono, 2010).

Penyajian data adalah hasil dari reduksi data, disajikan dalam laporan yang sistematis dan mudah dibaca atau dipahami baik secara menyeluruh maupun bagian-bagiannya (Sugiono,2010). Selanjutnya, penarikan kesimpulan yang disampaikan bersifat sementara dan akan berubah apabila tidak diperoleh fakta-fakta yang kuat untuk mendukung pada tahap pengumpulan data selanjutnya (Sugiyono,2010).

\section{HASIL DAN PEMBAHASAN}

Program Keluarga Harapan adalah program yang memberikan bantuan langsung kepada masyarakat untuk meningkatkan kualitas hidup melalui akses pendidikan dan kesehatan, melalui pemberian bantuan yang bersyarat (Suleman et. al,2019). Dalam melaksanakan PKH dibutuhkan perencanaan, pengorganisasian, pengarahan dan pengawasan (Wulandari, 2017). 
PKH berfokus dalam bidang kesehatan dan pendidikan (Dheby, Adhys \& Idris, 2017; Husodo, 2019). Strategi dalam menjalankan PKH adalah mengubah pola pikir masyarakat agar generasi penerus bangsa sehat dan cerdas, sehingga kemiskinan dapat teratasi dengan sendirinya (Roidah, 2016). Menurut (Ridho, 2019) sasaran penerima PKH adalah keluarga rentan dan miskin, dalam bidang kesehatan, pendidikan dan kesejahteraan sosial. 6 hal yang mempengaruhi implementasi adalah ukuran dan tujuan kebijakan, sumber daya, karakteristik agen pelaksana, sikap para pelaksana, komunikasi antar organisasi dan aktivitas pelaksana dan lingkungan ekonomi, sosial dan politik (Londah, Tampi, \& Londa, 2018; Bakhtiar \& Qodir, 2016).

Dana yang digunakan untuk Pogram Keluarga Harapan bersumber dari APBN serta didukung dana APBD disetiap daerah dan hambatan PPKH adalah kurangnya komitmen Sumber Daya Manusia, komunikasi yang sulit, letak geografis, masih banyaknya masyarakat yang belum paham tentang PKH dan sulitnya jaringan internet dalam proses penarikan (Edu \& Rohman, 2019; Domri, Ridwan, \& Jaya, 2019; Susanti, 2018). Faktor pendukung kinerja UPPKH dalam meningkatkan produktivitas $\mathrm{PKH}$ adalah pelayanan yang ramah, tanggap dan jelas kepada masyarakat, fasilitas dan dukungan kebijakan, dukungan sosial, sarana prasarana yang tersedia, biaya, akses, dan proses pengambilan keputusan (Sani, 2016; Marnah, Husaini, \&llmi, 2017; Daud, 2018). Diperlukannya komunikasi yang baik dan lancer antara Dinas Sosial dengan peserta $\mathrm{PKH}$ dalam pendampingan $\mathrm{PKH}$ (Sasmito, C \&Nawangsari, E. R 2019).

Perilaku masyarakat dalam pemanfaatan pelayanan kesehatan peserta $\mathrm{PKH}$ dipengaruhi oleh factor predisposisi adalah pengetahuan, keyakinan peserta $\mathrm{PKH}$ dalam pemanfaatan pelayanan kesehatan, pengalaman, kebiasaan, nilai budaya dan rasa kenyamanan masyarakat. Terakhir, factor pemungkin adalah sikap dari petugas penyedia layanan kesehatan, kebijakandari program $\mathrm{PKH}$, serta administrasi yang menyulitkan masyarakat dalam mendapatkan pelayanan (Marnah, Husaini, \&llmi, 2017).

Program PKH dikatakan sukses apabila dipengaruhi oleh perencanaan program yang matang, pendamping $\mathrm{PKH}$ yang bekerja keras untuk mendampingi penerima $\mathrm{PKH}$, serta orang tua penerima PKH yang mampu menerapkan sosialisasi dari pendamping PKH untuk meningkatkan pendidikan anak-anaknya (Aminuddin \& Syir'ah, 2016). Pertemuan Peningkatan Kemampuan Keluarga (P2K2) diselenggarakan tiap satu bulan sekali. Adapun model komunikasi pemberdayaan masyarakat yang digunakan oleh pendamping social dalam menyampaikan pesan P2K2 adalah komunikasi persuasive, Komunikasi Dialogis, Validasi wawancara dan Observasi, Model penyebaran arus komunikasi, Pemerintah (Fatimah, Arifin \& Sumpena, 2019).

Tabel 2. Jumlah Penduduk Miskin Menurut Kabupaten/Kota di Daerah Istimewa Yogyakarta Tahun 2018

\begin{tabular}{clc}
\hline No & \multicolumn{1}{c}{ Kabupaten } \\
\\
\hline 1 & Daerah Istimewa Yogyakarta & \\
2 & Kulon Progo & 460,10 \\
3 & Bantul & 77,72 \\
4 & Gunung Kidul & 134,84 \\
5 & Sleman & 125,76 \\
6 & Yogyakarta & 92,04 \\
\hline
\end{tabular}

(Sumber: Data ini diambil dari website Badan Pusat Stastik (BPS) Kabupaten Bantul Tahun2018).

Menurut (Hidayat, 2018) dampak pelaksanaan PKH adalah mengurangi beban perekonomian penerima $\mathrm{PKH}$ dan meningkatkan pendidikan anak-anak, mengurangi tingkat pekerja anak, serta mengurangi anak putus sekolah, peningkatan kualitas pelayanan 
pendidikan dan kesehatan, jangkauan pemerataan taraf pendidikan, aksesibilitas kesehatan bagi ibu hamil dan menyusui dan perbaikan produktivitas. (Hidayat, 2018; Rentianti, 2017). Adanya timbal balik antara petugas pelaksana program dengan penerima $\mathrm{PKH}$, yaitu saling menguntungkan karna masyarakat dapat mengikuti program sesuai dengan aturan (Parwati, 2018).

\section{Grafik Penduduk Miskin Daerah Istimewah Yogyakarta Tahun 2018}

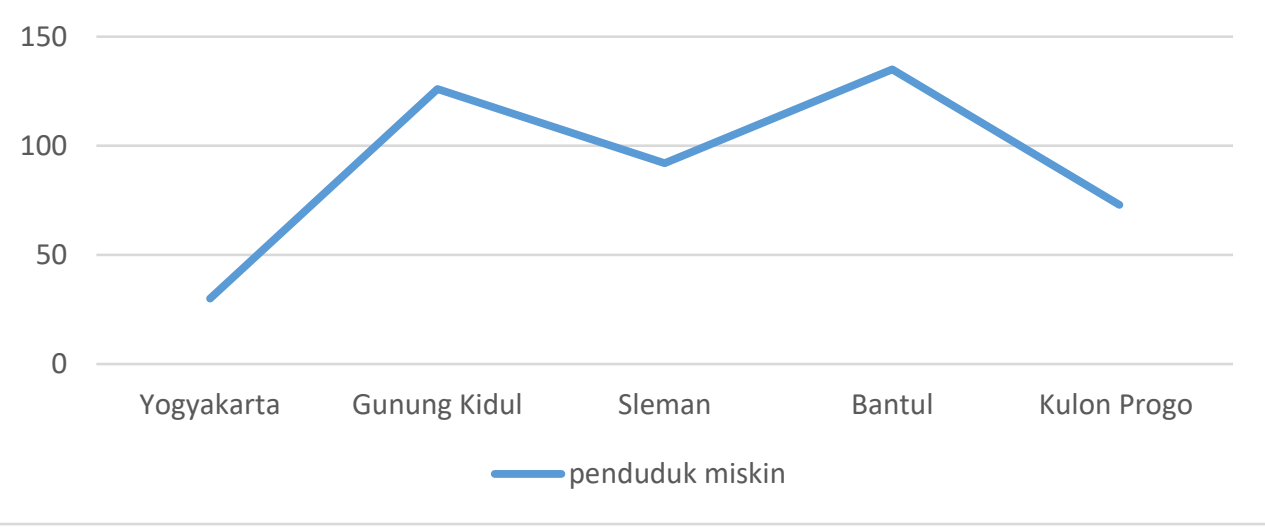

Gambar 1. Grafik Penduduk Miskin Daerah Istimewa Yogyakarta Tahun 2018

Tabel 3. Presentasi Penduduk Miskin Kabupaten Bantul Tahun 2013-2018

\begin{tabular}{rrrrrrrr}
\hline NO & KABUPATEN & \multicolumn{7}{c}{ TAHUN } \\
& & $\mathbf{2 0 1 3}$ & $\mathbf{2 0 1 4}$ & $\mathbf{2 0 1 5}$ & $\mathbf{2 0 1 6}$ & $\mathbf{2 0 1 7}$ & $\mathbf{2 0 1 8}$ \\
\hline 2. & Bantul & $16,48 \%$ & $15,89 \%$ & $16,33 \%$ & $14,55 \%$ & $14,07 \%$ & $13,43 \%$ \\
\hline
\end{tabular}

(Sumber: Data inidi ambil dari website Badan Pusat Stastik (BPS) Kabupaten Bantul Tahun 2018).

Terbatasnya akses keberbagai sector ekonomi dan sumber daya alam menyebabkan masyarakat hidup dalam kondisi miskin. Berdasarkan Peraturan Presiden Republik Indonesia Nomor 15 Tahun 2010 mengenai Laju Penyelesaian Kemiskinan jika kemiskinan adalah masalah bangsa bersifat darurat serta membutuhkan tindakan-tindakan untuk menangani dan pendekatan secara terstruktur, menyeluruh dan terpadu dengan tujuan untuk meminimalisir beban dan member hak-hak dasar warga Negara melalui pembangunan inklusif, adil dan berkesinambungan secara layak agar menciptakan kehidupan yang bermartabat.

Program penanggulangan kemiskinan adalah suatu aktivitas pemerintah, baik pusat atau pun daerah, swasta, masyarakat dalam rangka menaikkan kesejahteraan penduduk miskin lewat bantuan sosial, pemberdayaan masyarakat, dan program lain untuk memperbaiki aktivitas ekonomi (Sari, 2019).

Program penanggulangan kemiskinan meliputi:

a. Kelompok program bantuan sosial yang terarah berbasis keluarga, dengan tujuan mencukupi hak dasar, menyusutkan masalah hidup dan membenahi kapasitas hidup masyarakat miskin.

b. Kelompok program untuk menanggulangi kemiskinan yang berbasis pemberdayaan masyarakat dengan tujuan untuk pengembangan kemampuan serta meningkatkan kekuatan masyarakat miskin agar berpartisipasi dalam hal pembangunan yang 
berpedoman pada dasar-dasar pemberdayaan masyarakat (Sari, E. P, 2019). Penyebab kemiskinan, yaitu:

a) Adanya ketidaksamaan dalam kepemilikan sumber daya, sehingga penghasilan minim atau kurang. Penduduk miskin hanya memiliki sumber daya yang kualitasnya rendah dan terbatas.

b) Potensi sumber daya manusia yang rendah, sehingga produktivitas rendah dan gaji rendah, maka memunculkan kemiskinan. Produktivitas penduduk miskin rendah sehingga upah yang didapat rendah.

c) Perbedaan akses dan modal juga mengakibatkan kemiskinan (Husodo, 2019).

Penduduk miskin atau keluarga miskin memiliki ciri-ciri, yaitu:

a. Tidak memiliki penyebab produksi misalnya peralatan kerja, tanah, keterampilan dan modal.

b. Kualitas pendidikan yang dimiliki rendah.

c. Bekerja dan berusaha sendiri, sehingga bersifat usaha kecil, setengah menganggur.

d. Kebanyakan berada di daerah perkotaan tertentu dan pedesaan.

e. Minimnya kesempatan untuk mendapatkan bahan kebutuhan pokok, perumahan, fasilitas komunikasi, pakaian dan kesejahteraan lainnya (Ernawati, \& Listyaningsih, 2012).

Tanda-tanda kemiskinan adalah:

a. Rumah tidak layak pakai dan dibangun dari materi bangunan yang berkualitas rendah.

b. Peralatan kurang.

c. Perekonomian yang rendah atau pendapatan yang minim.

Langkah cepat untuk menanggulangi kemiskinanya itu dengan:

a) Memangkas pengeluaran penduduk miskin

b) Menambah pendapatan dan kemampuan penduduk miskin

c) Menjamin dan mengembangkan keberanjutan Usaha Mikro dan Kecil

d) Mensinergikan kebijakan dan program untuk menanggulangi kemiskinan (Sari, 2019).

Upaya pemerintah Indonesia dalam rangka pengentasan kemiskinan adalah dengan adanya $\mathrm{PKH}$. Maksud $\mathrm{PKH}$ adalah upaya dalam rangka membentuk perlindungan social penduduk miskin untuk meningkatkan kesejahteraan social serta memutus rantai kemiskinan. $\mathrm{PKH}$ adalah program bersyarat yang diharapkan dapat bermanfaat bagi masyarakat miskin terutama dalam bidang kesehatan dan pendidikan.

Program Kelarga Harapan adalah program bantuan tunai yang bersyarat dalam bidang pendidikan dan kesehatan. PKH diharapkan dapat menolong keluarga miskin untuk menaikkan kualitas hidup serta dapat memutus rantai kemiskinan (Susanto, 2016). Program Keluarga Harapan adalah program yang memberikan bantuan langsung kepada masyarakat untuk meningkatkan kualitas hidup melalui akses pendidikan dan kesehatan, melalui pemberian bantuan yang bersyarat (Suleman \& Resnawaty, 2017; Ahmad, Martuti, dkk, 2019; Ayu \& Satmoko, 2018). Dalam melaksanakan PKH dibutuhkan perencanaan, pengorganisasian, pengarahan dan pengawasan (Wulandari, 2017).

PKH berfokus dalam bidang kesehatan dan pendidikan (Dheby, Adhys, \& Idris, , 2017; Husodo, 2019). Strategi dalam menjalankan PKH adalah mengubah pola piker masyarakat agar generasi penerus bangsa sehat dan cerdas, sehingga kemiskinan dapat teratasi dengan sendirinya (Roidah, 2016). Menurut (Ridho, 2019) sasaran penerima PKH adalah keluargarentan dan miskin, dalam bidang kesehatan, pendidikan dan kesejahteraan sosial. 6 hal yang mempengaruhi implementasi adalah sumber daya, size serta maksud atau tujuan dari kebijakan, sikap para pelaksana, cirri agen pelaksana, terjaganya komunikasi setiap organisasi dan aktivitas pelaksana dan politik dan sosial, lingkungan ekonomi (Londah, Tampi, \& Londa, 2018; Bakhtiar, \& Qodir, 2016). Peran keluarga, yaitu: 
a. Modelling. Orang tua adalah panutan anak-anaknya. Perilaku seorang anak, terbentuk karena perilaku orang tuanya.

b. Mentoring atau Pengawasan. Yaitu dengan membangun hubungan dan memberikan perlindungan.

c. Organizing. Adalah menyelesaian masalah, tugas dengan kerjasama tim.

d. Teaching. Orang tua mengajarkan kepada anak-anaknya tentang norma-norma kehidupan (Setiani, T, 2014).

Landasan Hukum Pemberian PKH yaitu:

1. UU Nomor 40 Tahun 2004 mengenai Sistem Jaminan Sosial Nasional.

2. UU Nomor 13 Tahun 2011 mengenai Pengurusan Fakir Miskin.

3. Perpres Nomor 15 Tahun 2010 mengenai Laju Penyelesaian Kemiskinan.

4. Intstruksi Presiden Nomor 3 Tahun 2010 mengenai Program Pembangunan yang Berkeadilan poin lampiranke 1 sebagai penyempurna Pelaksanaan Program Keluarga Harapan.

5. Instruksi Presiden Nomor 1 Tahun 2013 Mencegah dan Memberantas Korupsi poin lampiran ke 46 tentang Pelaksanaan Transparansi Penyaluran Bantuan Langsung Tunai Bersyarat untuk Keluarga Sangat Miskin (KSM) Sebagai Peserta PKH (Husodo, E. S, 2019).

Sasaran Program Keluarga Harapan (PKH):

a. Memperbaiki status ekonomi dan social masyarakat miskin

b. Menaikkan kualitas pendidikan dan kesehatan anak masyarakat miskin

c. Memperbaiki taraf pendidikan dan kesehatan masyarakat miskin.

Proses Pelaksanaan Program Keluarga Harapan (PKH):

a. Menyediakan data calon peserta PKH (data berdasarkan BPS)

b. Menetapkan tempat serta menentukan atau menetapkan sasaran

c. Mengecek aktualitas serta validasi calon kandidat PKH

d. Membayar langsung yang meliputi: Pelunasan awal sesudah validasi peserta dan Pelunasan berikutnya sesuai hasil pemeriksaan untuk anggota lain.

e. Pemeriksaan ketaatan kewajiban

f. Pemulihan atau pembaharuan data (Saraswati, 2018). yaitu:

Data peserta PKH diperoleh dari Basis Data Terpadu dan melengkapi minimal 1 criteria

a. Di dalam keluarga terdapat balita/ibu hamil/nifas

b. Ada anggota keluarga usia 5-7 tahun yang belum masuk pendidikan dasar

c. Ada anggota keluarga usia 7-12 tahun SD/MI/Paket A/SDLB

d. Ada anggota keluarga usia 12-15 tahun SLTP/MTs/Paket B/SMLB

e. Ada anggota keluarga usia 15-18 tahun yang belum selesai pendidikan dasar termasuk anak disabilitas.

Semua keluarga berhak mendapatkan bantuan tunai jika mencukupi standar peserta program dan melengkapi kewajiban sebagai peserta PKH. Apabila peserta dalam satu triwulan tidak memenuhi kewajiban dan komitmennya maka bantuan yang diperoleh akan berkurang, berikut rinciannya:

a. Apabila dalam satu bulan peserta PKH tidak menyanggupi kewajiban, bantuan akan terpotong sebanyak Rp. 50.000,00

b. Jika dalam dua bulan anggota $\mathrm{PKH}$ tidak menyanggui kewajibannya, bantuan akan terpotong sebanyak Rp. 100.000,00 
c. Jika dalam 3 bulan peserta PKH tidak menyanggupi kewajibannya secara berturut-turut, maka tidak akan mendapatkan bantuan dalam satu periode pembayaran (Sari, E. P, 2019).

PKH ini membantu untuk mencapai tujuan Pembangunan Millenium, ada 5 komponen yaitu mengurangi masyarakat miskin dan kelaparan, kesetaraan gender, pendidikan dasar, mengurangi jumlah kematian bayi atau balita, mengurangi jumlah kematian ibu melahirkan. PKH diharapkan mampu meminimalisir pengeluaran untuk Keluarga Miskin (KM). Sedangkan dalam jangka panjang, PKH ini diharapkan mampu memotong rantai kemiskinan untuk menghasilkan generasi yang cerdas dan sehat. Sedangkan tujuan khusus PKH adalah sebagai berikut:

a. Memperbaiki status ekonomi social Rumah Tangga Sangat Miskin (RTSM)

b. Menaikkan kualitas kesehatan ibu hamil, nifas dan anak balita serta anak usia 5-7 tahun yang belum masuk sekolah dasar.

c. Menaikkan kualitas dan jalan masuk pelayanan pendidikan dan kesehatan, terutama bagi RTSM (Saraswati, A, 2018).

1. Dasar Pelaksanaan PKH

a. Keputusan Menteri Koordinasi Bidang Kesejahteraan Rakyat selaku ketua Tim Koordinasi Penanggulangan Kemiskinan, No: 31/KEP/MENKO/-KESRA/IX/2007 tentang "Tim Pengendali Program Keluarga Harapan" .

b. Keputusan Menteri Sosial Republik Indonesia No. 02A/HUK/2008 tentang "Tim Pelaksana Program Keluarga Harapan (PKH) Tahun 2008".

2. Hak dan Kewajiban anggota PKH

Peserta PKH harus melengkapi persyaratan untuk turut berperan aktif agar program ini dapat berjalan dengan lancar. Kewajiban peserta $\mathrm{PKH}$ yang harus dilaksanakan adalah :

a. Pendidikan. Peserta PKH wajib hadir dalam satuan pendidikan minimal $85 \%$ selama tahun ajaran berlangsung, dengan catatan sebagai berikut:

a) Keluarga peserta PKH memiliki anak yang berusia 5-6 tahun dan masuk SD maka dikenakan persyaratan pendidikan.

b) Apabila dalam keluarga anggota PKH memiliki anggota keluarga berusia 7-15 tahun harus didaftarkan pada satuan pendidikan.

c) Apabila dalam keluarga peserta PKH terdapat anak usia 15-18 tahun yang belum menuntaskan pendidikan dasar wajib mendaftarkan anaknya ke instansi pendidikan yang mengadakan program wajib belajar 9 tahun.

d) Jika terdapat anggota keluarga yang masih buta aksara, harus ikut pendidikan keaksaraan fungsional di Pusat Kegiatan Belajar Masyarakat (PKBM) yang dekat.

e) Jika terdapat anggota keluarga yang bekerja atau meninggalkan sekolah maka harus didaftarkan pada Dinas Tenaga Kerja dan Dinas Pendidikan tingkat Kabupaten/Kota untuk mengurangi pekerja dalam kategori anak.

f) Jika terdesak hidup dijalanan dan sudah tidak sekolah dalam waktu yang cukup lama, maka anak tersebut didaftarkan kepada Dinas Sosial dan Dinas Pendidikan ditingkat Kabupaten/Kota untuk memperoleh Program Kesejahteraan Sosial Anak.

b. Kesehatan.

Untuk usia 0-6 tahun:

a) Periksa kesehatan $3 x$ untuk anak usia 0-28 hari.

b) Imunisasi lengkap dan timbang berat badan secara rutin setiap bulan untuk anak usia 6-11 bulan.

c) Memperoleh vitamin A paling sedikit 2x dalam setahun untuk anak usia 6-11 tahun.

d) Memantau tumbuh kembang anak dan menimbang berat badan rutin setiap bulan untuk anak usia 5-6 tahun.

Untuk ibu hamil dan ibu nifas: 
a) Ibu hamil memeriksakan kehamilan sebanyak $4 \mathrm{x}$ adalah $1 \mathrm{X}$ pada usia $0-3$ bulan kehamilan, $1 \mathrm{X}$ pada usia 4-6 bulan, dan $2 x$ pada usia 7-9 bulan di fasilitas kesehatan.

b) Saat melahirkan wajib dibantu oleh karyawan kesehatan di fasilitas kesehatan.

c) Bagi ibu nifas dicek kesehatan serta mendapatkan pelayanan KB setelah persalinan minimal 3x pada minggu 1, 4 dan 6.

c. Penyandang Disabilitas Berat

a) Memberikan kesehatan cocok dengan keperluan

b) Pelayanan kesehatan dapat dikerjakan dengan mengunjungi rumah bagi tenaga kesehatan.

d. Lansia diatas 70 Tahun

a) Memberikan pelayanan kesehatan oleh karyawan kesehatan atau berkunjung ke puskesmas.

b) Mengikuti kegiatan sosial.

\section{Sedangkan hak-hak anggota PKH adalah:}

a. Memperoleh subsidi uang secara langsung sesuai dengan peraturan program.

b. Memperoleh fasilitas dan pelayanan pendidikan dan kesehatan untuk semua anggota keluarga.

c. Memperoleh program sinergitas penanggulangan kemiskinan yang lainnya.

d. Terpenuhi kebutuhan dasar serta pelayanan kesehatan yang sesuai dengan kebutuhan untuk lansia 70 tahun keatas dan penyandang disabilitas berat.

Sebagian besar masyarakat miskin di Kabupaten Bantul hanya tamat Sekolah Menengah Pertama (SMP). Di Kabupaten Bantul untuk mengetahui sejauh mana pemahaman masyarakat tentang PKH yitu dengan sosialisasi. Sosialisasi program dibutuhkan untuk mengukur efektivitas program yang dijalankan (Astari \& Pambudi, 2018). Sosialisasi program dikatakan sukses apabila informasi mengenai $\mathrm{PKH}$ tersampaikan dengan baik kepada masyarakat penerima PKH. Dinas Sosial Kabupaten Bantul melaksanakan sosialisasi PKH setahun sekali secara rutin dengan mengundang pihak-pihak tertentu seperti puskesmas, Dukuh, camat dan pendamping $\mathrm{PKH}$. Sosialisasi bertujuan untuk memonitoring kinerja pendamping $\mathrm{PKH}$. Stakeholders melakukan evaluasi dan koordinasi apabila terdapat masalah-masalah di masyarakat.

Sedangkan pendamping PKH melaksanakan sosialisasi sebulan sekali dengan masyarakat penerima PKH. Untuk memudahkan masyarakat penerima $\mathrm{PKH}$ menyampaikan keluhan dan pengaduannya, maka dibutuhkan komunikasi dengan pendamping $\mathrm{PKH}$. Selain itu, ketepatan sasaran di suatu program sangat penting. Sasaran $\mathrm{PKH}$ yaitu masyarakat yang dinyatakan lolos sebagai penerima bantuan PKH (Astari, U. T \&Pambudi, A, 2018). Pendamping PKH dan DinasSosial Kabupaten Bantul tidak dapat menghapus data masyarakat penerima $\mathrm{PKH}$, karena data didapat dari pusat. Sehingga pendamping $\mathrm{PKH}$ hanya dapat memproses sesuai dengan data yang diberikan. Selain itu, adanya program Pengurangan Pekerja Anak dalam rangka mendukung Program Keluarga Harapan (PPA$\mathrm{PKH}$ ) adalah kegiatan menarik pekerja anak dari Rumah Tangga Sangat Miskin (RTSM) yang putus sekolah. Dampak positif yang diterima oleh peserta setelah mengikuti program PPAPKH di Kabupaten Bantul adalah peserta dapat bersosialisi baik dengan teman dan lingkungan sekitarnya, peserta mempunyai semangat yang lebih untuk kembali menempuh pendidikan dan peserta lebih rajin dalam menjalankan ibadah sesuai dengan kepercayaannya masing-masing. Dalam pelaksanaan program ini tidak adadampak negatif yang diterima oleh peserta karena seluruh rangkaian kegiatan berdampak positif. Sumber daya manusia yang melaksanakan program PPA-PKH adalah dinas tenaga kerja dan transmigrasi kabupaten/kota yang ada di seluruh Indonesia. Dalam pelaksanaan program PPA-PKH di Kabupaten Bantul dilaksanakan secara langsung oleh Dinas Tenaga Kerja dan Transmigrasi Kabupaten Bantul. Dalam pelaksanaannya Dinas Tenaga Kerja dan Transmigrasi Kabupaten Bantul dibantu oleh beberapa pendamping. 
Dalam mencairkan bantuan PKH di Kabupaten Bantul, dibutuhkan ketepatan waktu. Bantuan PKH ini keluar setiap 3 bulan sekali untuk masyarakat penerima PKH dengan cara dikirim ke masing-masing rekening penerima $\mathrm{PKH}$. Agar berjalan dengan efektif dan efisien, maka stakeholders sangat dibutuhkan dalam pelaksanaan PKH. Hambatan dalam pencairan bantuan $\mathrm{PKH}$ di kabupaten Bantul adalah keterlambatan pendamping $\mathrm{PKH}$ dalam memberikan laporan ke pusat. Keterlambatan itu disebabkan karena minimnya jumlah pendamping $\mathrm{PKH}$, sehingga beban kerja yang mereka dapat terlalu banyak.

Dalam melaksanakan program, para pelaksana wajib menyampaikan laporan pertanggung jawabannya kepada UPPKH Kabupaten. Selanjutnya, UPPKH juga wajib menyampaikan pertanggungjawabannya kepada UPPKH Pusat. Program Keluarga Harapan (PKH) di Kabupaten Bantul dikatakan belum sepenuhnya dapat mengubah perekonomian masyarakat penerima $\mathrm{PKH}$, dikarenakan besaran atau jumlah bantuan dirasa belum adil untuk masyarakat mengingat setiap keluarga memiliki anggota keluarga yang berbeda-beda (Astari, \& Pambudi, 2018). Terdapat beberapa hambatan dalam pelaksanaan PKH di Kabupaten Bantul, yaitu:

a. Minimnya dana untuk memberikan saran dan prasarana pendukung bagi pelaksana $\mathrm{PKH}$.

b. Kurangnya ketersediaan sumber daya manusia yaitu pendamping $\mathrm{PKH}$.

c. Menurunnya kepatuhan peserta PKH.

d. Data penerima PKH tidak diperbarui sehingga kurang tepat sasaran.

Dalam pemberian dana, Pemerintah Kabupaten Bantul ikut membantu yaitu dana yang berasal dari APBD untuk pelaksanaan PKH, serta Dinas Sosial Kabupaten Bantul membantu dalam memberikan fasilitas $\mathrm{PKH}$. Selain adanya pertemuan rutin antara pendamping dengan peserta $\mathrm{PKH}$, juga diadakan pendidikan dan pelatihan Keluarga Penerima Manfaat (KPM). Pendidikan dan pelatihan adalah sebuah kegiatan yang ada dalam pertemuan rutin tersebut. Terdapat 6 tema utama yang wajib disampaikan ke Keluarga Penerima Manfaat (KPM) tersebut yaitu:

a. Bidang Kesehatan. Dengan meningkatkan gizi, pelayanan ibu hamil dan bersalin, ibu nifas dan menyusui serta Perilaku Hidup Bersih dan Sehat (PHBS).

b. Bidang Pendidikan. Dengan meningkatkan perilaku baik anak, menolong anak sukses disekolah serta mencermati tingkah dan belajar anak usia dini.

c. Bidang Ekonomi. Dengan pengelolaan keuangan keluarga, kredit dan tabungan, kewirausahaan dan pemasaran serta manajemen usaha mikro kecil menengah.

d. Bidang Kesejahteraan Sosial Lansia. Dengan memberikan pemahaman kondisi dan kebutuhan lansia, memberikan dukungan dari keluarga dan masyarakat terhadap lansia.

e. Bidang layanan untuk disabilitas berat, mengenal jenis-jenis disabilitas, perawatan yang dibutuhkan serta dukungan dari keluarga dan masyarakat.

f. Bidang Perlindung ananak. Yaitu mencegah kekerasan dalam Rumah Tangga, perlindungan terhadap ibu dan anak (Riswantoro, 2018).

Dengan adanya 6 tema utama tersebut, maka KPM atau peserta PKH tersebut dapat menjadikan dirinya lebih produktif, sebab terdapat pelatihan kewirausahaan. Pelatihan kewirausahaan tersebut, dapat menjadikan KPM lebih kreatif serta dapat meningkatkan pendapatan dalam keluarganya.

\section{SIMPULAN DAN SARAN}

Program Keluarga Harapan adalah program bantuan tunai yang bersyarat dalam bidang pendidikan dan kesehatan. PKH ini membantu untuk mencapai tujuan Pembangunan Millenium, ada 5 komponen yaitu mengurangi penduduk miskin dan kelaparan, kesetaraan 
gender, pendidikan dasar, mengurangi angka kematian bayi dan balita, dan mengurangi angka kematian ibu melahirkan. Kabupaten Bantul untuk mengetahui sejauh mana pemahaman masyarakat tentang $\mathrm{PKH}$ yitu dengan sosialisasi. Sosialisasi bertujuan untuk memonitoring kinerja pendamping $\mathrm{PKH}$. Sasaran $\mathrm{PKH}$ yaitu masyarakat yang dinyatakan lolos sebagai penerima bantuan PKH. Hambatan PKH di Kabupaten Bantul adalah minimnya dana untuk memberikan sarana dan prasarana pendukung bagi pelaksana $\mathrm{PKH}$, kurangnya ketersediaan sumber daya manusia yaitu pendamping $\mathrm{PKH}$, menurunnya kepatuhan peserta $\mathrm{PKH}$, dan data penerima PKH tidak diperbarui sehingga kurang tepat sasaran.

Penelitian ini menyarankan untuk melibatkan pemerintahan desa agar ada yang memonitoring secara langsung, masyarakat memenuhi kewajiban-kewajiban sebagai peserta $\mathrm{PKH}$, adanya pembaruan data peserta $\mathrm{PKH}$.

\section{UCAPAN TERIMA KASIH}

Pada penelitian ini saya mengucapkan terimakasih kepada program studi IImu Pemerintahan yang telah memberikan dukungan untuk dapat menerbitkan artikel penelitian yang telah saya lakukan selama satu semester dengan supervise daridosen senior IImu Pemerintahan Universitas Muhammadiyah Yogyakarta, yakni EkoPriyo Purnomo, S.IP., M.Si., M. Res., Ph.D., dan Aulia Nur Kasiwi, S.IP., M.IP selama proses pelaksanaan kurang lebih 6 bulan lamanya.

\section{DAFTAR PUSTAKA}

Afrizal, A., \& Eliza, R. (2020). Pengaruh Program Keluarga Harapan (PKH) Terhadap Kesejahteraan Keluarga Penerima Manfaat di Kecamatan Tampan Kota Pekanbaru. Jurnal Mahasiswa IImu Administrasi Publik, 2(1), 118-127.

Angraeni, M. (2019). Pengaruh Program Keluarga Harapan (PKH) Terhadap Kondisi Sosial Ekonomi Rumah Tangga Miskin Perspektif Ekonomi Islam (Studi Pada Dusun Cisarua Desa Muara Putih Kecamatan Natar Kabupaten Lampung Selatan) [Doctoral dissertation] UIN Raden Intan Lampung.

Astari, U. T., \& Pambudi, A. (2018). Efektivitas Program Keluarga Harapan Di Kecamatan Pandak Bantul. Adinegara, 7(5), 692-705.

Dheby, C., Adys, A. K., \& Idris, M. (2017). Implementasi Program Keluarga Harapan Di Kecamatan Tamalate Kota Makassar. Kolaborasi: Jurnal Administrasi Publik, 3(2), 161-177.

Hidayat, S. (2018, August). Optimalisasi Program Keluarga Harapan (PKH): meliputi Partisipasi, Pemberdayaan, dan Kinerja Program Keluarga Harapan di Kecamatan Pulau Panggung. In Prosiding Seminar Nasional Darmajaya (Vol. 1, No. 1, pp. 194-202).

Hidayat, T. (2017). Penerapan Kriteria Reesi Sebagai Assessment Tools Monitoring dan Evaluasi Perencanaan Pembangunan Daerah Di Indonesia. Inovasi Pembangunan: Jurnal Kelitbangan, 5(03), 266-281.

Hidayati, E. F. S. (2019). Model pemberdayaan masyarakat miskin melalui Program Keluarga Harapan: Penelitian di Desa Puloerang, Kecamatan Lakbok, Kabupaten Ciamis [Doctoral dissertation] UIN Sunan Gunung Djati Bandung. 
Husodo, E. S., Halim, A., \& Zulkifli, Z. (2019). Partisipasi Masyarakat Dalam Program Keluarga Harapan (PKH) Di Kecamatan Ngombol Kabupaten Purworejo [Doctoral dissertation] STIE Widya Wiwaha.

Londah, A., Tampi, G. B., \& Londa, V. (2018). Implementasi Program Keluarga Harapan di Kecamatan Pasan Kabupaten Minahasa Tenggara. Jurnal Administrasi Publik, 4(53).

Ridho, R. (2019). Analisis Pelaksanaan Program Keluarga Harapan (PKH) Di Nagari Tanjuang Bungo Kecamatan Suliki Kabupaten Limapuluh Kota [Doctoral dissertation]. Universitas Islam Negeri Sultan Syarif Kasim Riau.

Riswantoro, R. (2018). Penyaluran Dari Tunai Ke Non Tunai: Studi Peran Pendamping dalam Mengawal Konversi PKH di Dlingo. Jurnal Pemberdayaan Masyarakat: Media Pemikiran dan Dakwah Pembangunan, 2(1), 43-66.

Roidah, I. S. (2016). Evaluasi Kebijakan Pengentasan Kemiskinan Dalam Program Keluarga Harapan Di Kecamatan Rejotangan Kabupaten Tulungagung. Jurnal AGRIBIS, 12(14), 3947.

Saraswati, A. (2018). Analisis Pengaruh Program Keluarga Harapan (PKH) Terhadap Pengentasan Kemiskinan Dalam Perspektif Ekonomi Islam (Studi Pada Pekon Pandansurat Kecamatan Sukoharjo Kabupaten Pringsewu) [Doctoral dissertation]. UIN Raden Intan Lampung).

Sari, E. P. (2019). Efektivtas Program Keluarga Harapan (PKH) Dalam Mengurangi Kemiskinan Di Kecamatan Way Tenong Kabupaten Lampung Barat.

Setiani, T. (2014). Analisis Pelaksanaan Program Keluarga Harapan (PKH) di Gampong Serba Jadi Kecamatan Darul Makmur Kabupaten Nagan Raya [Doctoral dissertation] Universitas Teuku Umar Meulaboh.

Sugiyono. (2010). Metode Peneitian Kuantitatif Kualitatif dan $R \& D$. Alfabeta, Bandung.

Suleman, S. A., \& Resnawaty, R. (2017). Program Keluarga Harapan (PKH): Antara Perlindungan Sosial dan Pengentasan Kemiskinan. Prosiding Penelitian dan Pengabdian kepada Masyarakat, 4(1), 88-92.

Susanto, H. (2017). Evaluasi Program Keluarga Harapan (Pkh) Di Kecamatan Kebayoran Lama Jakarta Selatan.

Wulandari, D. N., \& RFS, H. T. (2017). Pelaksanaan Program Keluarga Harapan (Pkh) Di Kota Pekanbaru (Studi Kasus Di Kelurahan Sri Meranti Kecamatan Rumbai). [Doctoral dissertation].Riau University.

Yudo, O. O., \& Purnomo, E. P. (2018). Implementasi Kebijakan Pengendalian Pencemaran Limbah Cair Hotel di Kota Yogyakarta Tahun 2017. Jurnal Administrasi Publik (Public Administration Journal), 8(2), 163-171. 